\title{
STUDIES ON THE PROPERTIES OF RETINAL ALCOHOL DEHYDROGENASE FROM THE RAT
}

\author{
W. D. WATKINS ${ }^{1}$ and T. R. TEPHLY \\ Department of Pharmacology, Medical School, University of Michigan, \\ Ann Arbor, Michigan 48104
}

(Received 27 November 1970. Accepted 14 May 1971)

\begin{abstract}
An NAD-dependent alcohol dehydrogenase (alcohol:NAD oxidoreductase; EC 1.1.1.1) has been isolated and partially purified from the retinal cytosol of the rat. Its substrate specificity and sensitivity to inhibitors of hepatic alcohol dehydrogenase have been investigated. Ethanol, 1-propanol and 1-butanol served as substrates for this enzyme but the $K_{m}$ values were more than 100-fold higher than those reported for hepatic alcohol dehydrogenase. Methanol and retinol were unreactive with this alcohol dehydrogenase. Inhibition by pyrazole was observed but the $K_{t}$ was about 100-fold higher than the value observed for hepatic alcohol dehydrogenase. $n$-Butyraldoxime inhibited retinal alcohol dehydrogenase with a $K_{t}$ of $2 \mu \mathrm{M}$, a value which approximates its $K_{t}$ for hepatic alcohol dehydrogenase. 1,10Phenanthroline was ineffective as an inhibitor. Oxidation of retinol was observed in retinal homogenates in the presence of NADP but no inhibition was observed with ethanol, methanol or pyrazole. We conclude that oxidation of retinol is not catalysed by soluble retinal alcohol dehydrogenase.
\end{abstract}

IT HAS been generally accepted that the retinol-retinaldehyde interconversion is mediated by alcohol dehydrogenase (ADH; alcohol: NAD oxidoreductase; EC 1.1.1.1). This concept ha been based primarily on observations that have been made using purified hepatic ADH (Bliss, 1951; ZACHMAN and OLSON, 1961; REYNIER, 1969) or crude preparations of retina (WALD and HUBBARD, 1949, 1963; READING and SORSBY, 1966; MUIRHEAD, 1967). However, KoEN and SHAW (1966) have presented evidence which suggests that the hepatic type of alcohol dehydrogenase is absent from the retina and that Vitamin $A$ alcohol (retinol) is oxidized in the retina and liver by specific and distinct enzymes.

Recent studies from this laboratory involved the use of inhibitors of hepatic ADH in order to inhibit in vivo the oxidation of methanol and ethanol (WATKINS, GooDMAN and TEPHLY, 1970). Pyrazole, a potent inhibitor of hepatic ADH (LESTER, KEOKOSKY and FELZENBERG, 1968), proved to be an effective inhibitor of the oxidation of ethanol and methanol in the monkey in vivo (WATKINS et al., 1970) but was relatively toxic in this species. BLÖMSTRAND and THEORELL (1970) have used 4-methylpyrazole in man. Because of the increasing use of these types of agents, we decided to investigate their effects on retinal ADH to determine whether or not they have toxic potential by virtue of inhibition of retinal $\mathrm{ADH}$. If retinal $\mathrm{ADH}$ participates in metabolism of visual pigments and if the retinal enzyme is similar to hepatic $\mathrm{ADH}$, these inhibitors could interrupt normal generation of visual pigments. Our present report demonstrates that purified retinal $\mathrm{ADH}$ has properties different from its hepatic counterpart and that it probably plays no role in the interconversion of retinol and retinaldehyde.

\footnotetext{
${ }^{1}$ Present address: Department of Pharmacology, University of Colorado Medical Center, Denver, Colorado.

Abbreviations used: ADH, alcohol dehydrogenase (EC 1.1.1.1); AldH, aldehyde dehydrogenase (EC 1.2.1.3); RADH, rat retinol alcohol dehydrogenase; RAldH, rat retinal aldehyde dehydrogenase.
} 


\section{Materials}

\section{MATERIALS AND METHODS}

$\mathrm{NAD}^{+}, \mathrm{NADH}, \mathrm{NADP}^{+}$, retinol (all-trans, type X), retinaldehyde (all-trans, type XVI), 1,10phenanthroline, DEAE-cellulose and CM-cellulose were purchased from Sigma Chemical Co. (St. Louis, Mo.). Pyrazole and 2-fluoroethanol were purchased from K \& K Laboratories (Plainville, N.Y.). $n$-Butyraldoxime was purchased from the Aldrich Chemical Co. (Milwaukee, Wis.). All other reagents employed in these studies were of the highest available purity. Rat livers and retinae were obtained from male Holtzman rats $(250 \mathrm{~g})$.

\section{Enzyme assays}

One unit of enzyme activity was defined as the amount of enzyme which catalysed the reduction of $1 \mu \mathrm{mol}$ of NAD per min under the conditions described. Specific activity was expressed as units $/ \mathrm{mg}$ of protein.

Alcohol dehydrogenase. ADH activity was routinely determined spectrophotometrically by measuring the reduction of $\mathrm{NAD}^{+}$at $340 \mathrm{~nm}$ on a Gilford 2000 spectrophotometer. Ambient temperature of the reaction medium was $25^{\circ} \mathrm{C}$. A final reaction mixture volume of $1.0 \mathrm{ml}$ contained: enzyme; $2 \mu \mathrm{mol}$ $\mathrm{NAD}^{+} ; 1 \mathrm{mmol}$ ethanol; $50 \mu \mathrm{mol}$ sodium pyrophosphate buffer $(\mathrm{pH} \mathrm{10} 0)$. Concentrations of acetone or Tween-80 which were used in the solubilization of retinol (REYNIER, 1969) did not inhibit the rate of NADH formation in this assay. In the absence of an alcohol substrate the concentrations of acetone and Tween-80 that were used in retinol solubilization did not provide NADH formation. During the course of this study a number of techniques were employed to investigate the enzymic oxidation of retinol to retinaldehyde other than the measurement of the rate of NADH formation.

(a) The enzymic formation of retinaldehyde was directly monitored by recording the rate of increase in extinction at $400 \mathrm{~nm}$ (REYNIER, 1969). This assay was employed to monitor retinaldehyde formation at each step in the purification procedure.

(b) The colorimetric determination of retinaldehyde followed the method of MALLIA and CAMA (1969).

(c) A colorimetric assay procedure for $\mathrm{ADH}$ was used in which measurement of propanediol generated from lactaldehyde was determined (GUPTA and ROBINSON, 1966). This assay has been described as a sensitive method for measurement of ADH in liver and brain (RASKIN and SokoLOFF, 1968).

(d) Certain retinal enzyme preparations were submitted to electrophoresis on analytical polyacrylamide disc gels, prepared by a modification of the basic formulation and procedure described by DIETz and LuBrano (1967). After electrophoretic migration, the gels were ordinarily incubated at $37^{\circ} \mathrm{C}$ in a medium containing substrate and a standard tetrazolium dehydrogenase-staining system buffered at $\mathrm{pH} 7 \cdot 6$. Standard gels were provided with ethanol as the substrate. Gels in which the retinol-oxidizing capacity was being investigated were incubated according to one of three schedules: (i) preliminary incubation in a medium consisting of buffer, retinol solubilized with Tween-80 (REYNER, 1969) and $\mathrm{NAD}^{+}$, followed by a second incubation in the buffered dye system only; (ii) single incubation in the buffered medium containing $\mathrm{NAD}^{+}$, dye system and retinol solubilized with Tween-80 or (iii) incubation identical to schedule (ii), with the exception that retinol was solubilized with acetone. Control studies were carried out in which each of the reaction components was withheld. This procedure was employed together with (a) at each step in the purification process. When either acetone or Tween-80 was included in the incubation mixture and alcohol substrate was omitted, no activity bands were observed. These solubilizing agents had no effect on the intensity of stain in bands formed when ethanol was employed as a substrate.

Aldehyde dehydrogenase. AldH (aldehyde: NAD oxidoreductase; EC 1.2.1.3) activity was determined spectrophotometrically, as already described for ADH. A final reaction mixture volume of $1.0 \mathrm{ml}$ contained: enzyme; $2 \mu \mathrm{mol} \mathrm{NAD}{ }^{+} ; 100 \mu \mathrm{mol}$ acetaldehyde and $50 \mu \mathrm{mol}$ sodium pyrophosphate buffer ( $\mathrm{pH} 9 \cdot 0$ ). Analysis of hepatic aldehyde dehydrogenase usually required inclusion of pyrazole, an alcohol dehydrogenase inhibitor, in order to prevent interference of alcohol dehydrogenase in the assay. This was unnecessary when aldehyde dehydrogenase from retinal preparations was assayed because of the poor affinity of acetaldehyde for retinal alcohol dehydrogenase.

Purification of rat retinal alcohol dehydrogenase $(R A D H)$ and rat retinal aldehyde dehydrogenase (RAldH).

Preparation of retinal cytosol fraction. Each of 50 rats was stunned and decapitated, and the eyes were rapidly removed and frozen at $-77^{\circ} \mathrm{C}$. The frozen eyes were trimmed free of any contiguous extraocular tissues. A single cut was made through the frontal portion of the eye, permitting in one dissecting operation a removal of the cornea, iris, lens, aqueous and vitreous humors. Studies utilized retinae which had been dissected free of connective tissue or more usually retinae with adjoining 
connective tissue; no enzymic differences were observed in these preparations. Retinae were homogenized $(0.5 \mathrm{ml}$ of buffer/retina) in Buffer $A(0.005 \mathrm{M}$-sodium pyrophosphate, $\mathrm{pH} 8.0$, containing $.0001 \mathrm{M}$-disodium EDTA and 0.0001 $\mathrm{M}$-dithiothreitol). All procedures described for this enzyme preparation were carried out at $0-4^{\circ} \mathrm{C}$. The homogenate was centrifuged at $12,500 \mathrm{~g}$ for $20 \mathrm{~min}$, and the resulting supernatant fraction was centrifuged at $105,000 \mathrm{~g}$ for $1 \mathrm{~h}$. The microsomal pellet was discarded, and most of the supernatant cytosol was subjected to the remaining purification procedures. The cytosol fraction contained all the $\mathrm{NAD}^{+}$-dependent ethanol oxidative activity. A portion of the cytosol was dialysed for $12 \mathrm{~h}$ against 100 vol. of Buffer $A$ at $\mathrm{pH} 8.0$ and was used for analysis of RADH and RAldH activities.

Ammonium sulphate fractionation. Appropriate quantities of $\left(\mathrm{NH}_{4}\right)_{2} \mathrm{SO}_{4}$ solution saturated at $4^{\circ} \mathrm{C}$ or of solid $\left(\mathrm{NH}_{4}\right)_{2} \mathrm{SO}_{4}$ were slowly added to the cytosol. The $\mathrm{pH}$ of the medium was maintained at $8 \cdot 0$ by the addition of small amounts of an $\mathrm{NH}_{4} \mathrm{OH}$ solution. The protein fractions precipitating in each of the saturation ranges $0-33 \%, 33-50 \%, 50-70 \%$ and $70-100 \%$ were individually dissolved in a minimal amount of Buffer $A(\mathrm{pH} 8.0)$ and dialysed against two changes of 100 vol. of Buffer $A$ over a 12-h period. Small portions of each dialysed $\left(\mathrm{NH}_{4}\right)_{2} \mathrm{SO}_{4}$ fraction were reserved for determination of RADH and RAldH activities. RADH and RAldH activities resided almost exclusively in the fractions at $33-100 \%\left(\mathrm{NH}_{4}\right)_{2} \mathrm{SO}_{4}$ saturation. Proteins precipitating in this range were pooled and subsequently submitted to DEAE-cellulose chromatography.

$D E A E$-cellulose chromatography. Proteins which precipitated after ammonium sulphate fractionation (33-100\%) were applied to a column of DEAE-cellulose $(1.8 \times 20 \mathrm{~cm})$ equilibrated with Buffer $A(\mathrm{pH} 8.0$ ) and were eluted with the same buffer. The flow rate was adjusted to about $30 \mathrm{ml} / \mathrm{h}$, and 6-ml fractions were collected. Fractions exhibiting RADH activity were pooled and stored at $-60^{\circ} \mathrm{C}$ for further studies. After the elution of RADH from the column, the pyrophosphate concentration for elution was changed from $0.005 \mathrm{M}$ to $0.05 \mathrm{M}$. RAldH activity was eluted by this solution, and the most active fractions were pooled and reserved for further studies.

\section{Studies on retinal homogenates}

Homogenates of rat retinae were prepared in $0.1 \mathrm{M}$-sodium phosphate buffer $(\mathrm{pH} 7 \cdot 6)$ and were examined for ability to oxidize retinol to retinaldehyde, by a modification of the method of READING and SorsBY (1966). Incubations were carried out in test tubes at $37^{\circ} \mathrm{C}$ under aerobic conditions. Reaction mixtures contained (per $\mathrm{ml}$ ): homogenate equivalent to $4 \mathrm{mg}$ of tissue; $1 \cdot 1 \mu \mathrm{mol}$ retinol; $2 \mu \mathrm{mol} \mathrm{NADP}{ }^{+}$and when used, $1 \mu \mathrm{mol}$ pyrazole; $100 \mu \mathrm{mol}$ ethanol and $100 \mu \mathrm{mol}$ methanol in a final volume of $1.5 \mathrm{ml}$ with $0.1 \mathrm{M}$-sodium phosphate buffer $(\mathrm{pH} 7.6)$. Reactions were carried out in dim light, and in a period of linear formation of retinaldehyde, portions were taken for estimation of retinaldehyde content by the method of MALLIA and CAMA (1969). No oxidation of retinol was observed after the enzyme preparation had been heated to $100^{\circ} \mathrm{C}$ for $10 \mathrm{~min}$, cooled and added to the incubation mixture, and no formation of retinaldehyde was measurable under these conditions in the absence of enzyme. Disappearance of retinaldehyde was negligible during the course of incubation.

The data employed to derive the kinetic constants were submitted to statistical analysis (WILKINSON, 1961), with calculations performed on an IBM 360/67 computer according to a Fortran program written by CLELAND (1963). Protein was estimated by the use of the biuret method (GoRNALL, BARDWILL and DAVID, 1949), u.v. absorption (WARBURG and CHRISTIAN, 1941) or the method of LoWRY, Rosebrough, FARR and RANDALL, 1951.

\section{RESULTS}

Separation and purification of alcohol dehydrogenase and aldehyde dehydrogenase from rat retina

Retinal NAD-dependent oxidation of ethanol (RADH) resided exclusively in the supernatant fraction obtained after centrifugation of the retinal homogenate at 105,000 $g$ for $1 \mathrm{~h}$. The cytosol is also the primary cellular locus of hepatic ADH. The relative solubilities of RADH and retinal aldehyde dehydrogenase (RAldH) were examined during $\left.\mathrm{NH}_{4}\right)_{2} \mathrm{SO}_{4}$ saturation of the rat retinal cytosol (Table 1). Most of the RADH precipitated in the range of 33-70\% $\left(\mathrm{NH}_{4}\right)_{2} \mathrm{SO}_{4}$ saturation, whereas most of the RAldH activity precipitated in the range of $70-100 \%\left(\mathrm{NH}_{4}\right)_{2} \mathrm{SO}_{4}$ saturation. Upon chromatography on DEAE-Cellulose of the cytosol fraction of retina or the 33-100\% $\left(\mathrm{NH}_{4}\right)_{2} \mathrm{SO}_{4}$ fraction of retinal cytosol, the elution pattern showed a complete separation of RADH and RAldH activity (Fig. 1). By contrast, it is not possible to resolve hepatic 
TABLE 1.--RELATIVE DISTRIBUTION OF ENZYMES FROM THE RAT RETINA AFTER AMMONIUM SULPHATE SATURATION

\begin{tabular}{ccc}
\hline & $\begin{array}{c}\mathrm{RADH}^{*} \\
(\% \text { of total activity in precipitate) }\end{array}$ \\
\hline $\left.\mathrm{NH}_{4}\right)_{2} \mathrm{SO}_{4}$ Saturation (\%) & 1 & 2 \\
$0-33$ & 18 & 10 \\
$33-50$ & 79 & 2 \\
$50-70$ & 2 & 86 \\
$70-100$ & 100 & 100 \\
Total & & \\
\hline
\end{tabular}

* Activity of retinal alcohol dehydrogenase (RADH) was determined spectrophotometrically at $25^{\circ} \mathrm{C}$ in a $1.0 \mathrm{ml}$ reaction mixture containing various concentrations of enzyme; $2 \mu \mathrm{mol} \mathrm{NAD}{ }^{+} ; 1 \mathrm{mmol}$ ethanol and $50 \mu$ mol sodium pyrophosphate buffer $(\mathrm{pH} 10 \cdot 0)$. Other special methods for retinal oxidation in these fractions are indicated in Methods.

$\dagger$ Activity of retinal aldehyde dehydrogenase (RAldH) was determined spectrophotometrically at $25^{\circ} \mathrm{C}$ in a $1.0 \mathrm{ml}$ reaction mixture containing various concentrations of enzyme; $2 \mu \mathrm{mol} \mathrm{NAD}{ }^{+} ; 100 \mu \mathrm{mol}$ acetaldehyde and $50 \mu \mathrm{mol}$ sodium pyrophosphate buffer $(\mathrm{pH} \mathrm{9.0)}$.

These data were taken from a representative experiment.

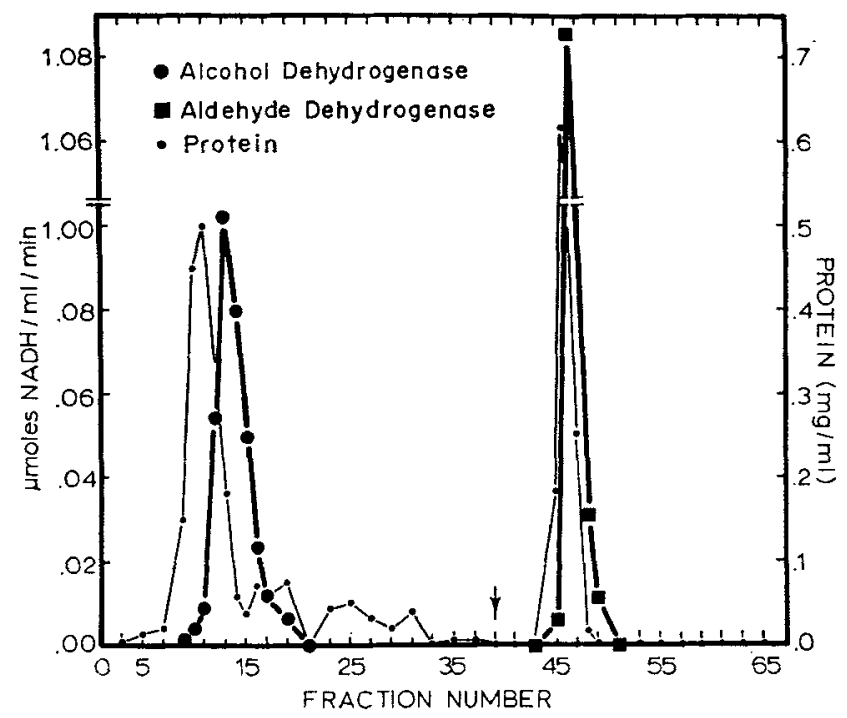

Fig. 1.-Chromatography of retinal enzymes on DEAE-cellulose. The dialysed precipitate following 33-100\% $\left(\mathrm{NH}_{4}\right)_{2} \mathrm{SO}_{4}$ saturation was applied to a column of DEAEcellulose and elution was begun with $0.005 \mathrm{M}(I=0.006)$ sodium: potassium phosphate buffer (pH 8.0) containing $1 \mathrm{~mm}-\mathrm{Na}_{2}$ EDTA and $0.1 \mathrm{~mm}$-dithiothreitol. At the point indicated by the arrow, the buffer concentration was increased 10-fold $(0.05 \mathrm{M})$. Enzyme activity was assayed as described in the Methods.

ADH from hepatic AldH by chromatography on DEAE-Cellulose of hepatic cytosol or a 33-100\% $\left(\mathrm{NH}_{4}\right)_{2} \mathrm{SO}_{4}$ precipitate of rat hepatic cytosol. Chromatographic separation of hepatic ADH and hepatic AldH usually requires chromatography on CMCellulose (REYNIER, 1969). Our purification procedures carried out on the rat retinal 
Retinal alcohol dehydrogenase

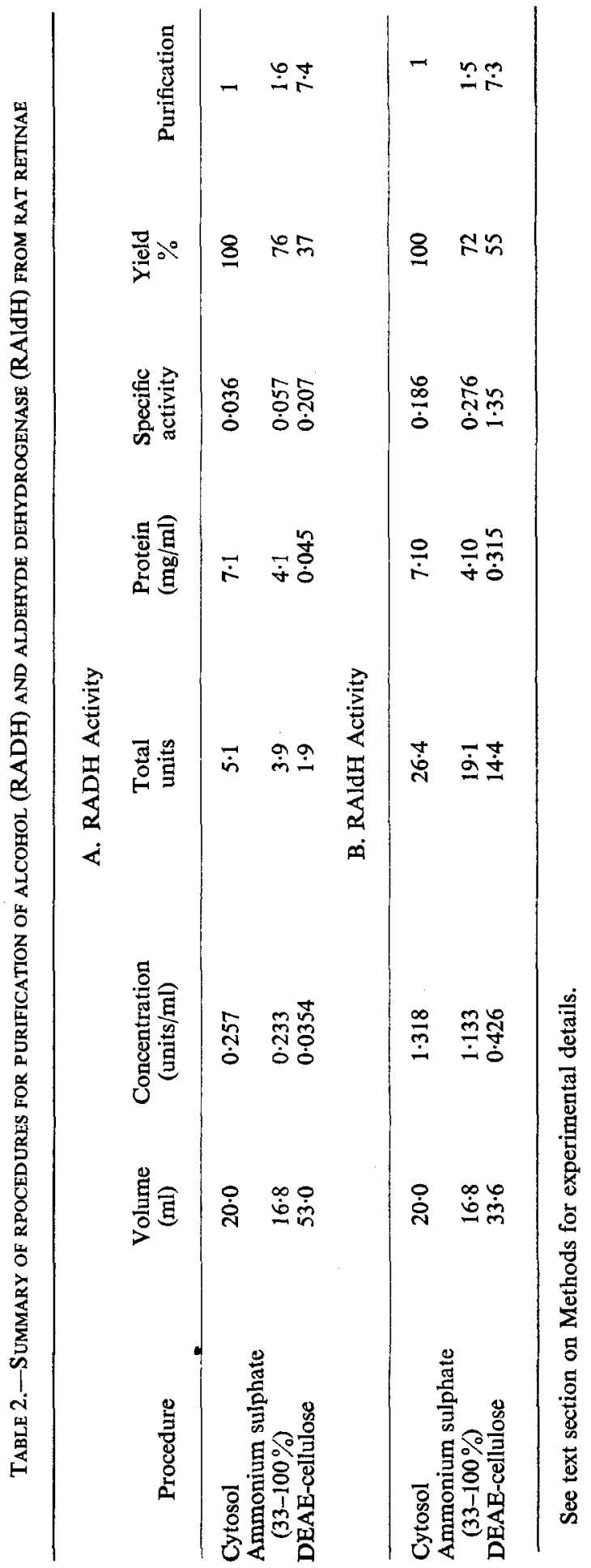


cytosol are summarized in Table 2 . The procedure achieved a complete separation of RADH from RAldH and 7.4- and 7·3-fold purifications, respectively, over the activities in the original cytosol preparation.

\section{Properties of rat retinal alcohol dehydrogenase}

Substrate specificity. The $\mathrm{pH}$ optimum for RADH was very similar to that observed for the hepatic enzyme, with maximal activity at $\mathrm{pH} 10 \cdot 0-10 \cdot 5$. All subsequent assays were carried out at $\mathrm{pH} 10 \cdot 0$. The activity of the RADH preparation was evaluated with a series of substrates known to be reactive with hepatic ADH (Table 3). The $K_{m}$ for $\mathrm{NAD}^{+}$in the presence of $1.0 \mathrm{M}$-ethanol was $0.4 \mathrm{mM}$. Methanol at concentrations up to $2.0 \mathrm{M}$ and retinol at concentrations up to $0.01 \mathrm{M}$ were unreactive with $\mathrm{RAdH}$.

TABLE 3.-SUBSTRATE SPECIFICITY OF RETINAL ALCOHOL DEHYDROGENASE

\begin{tabular}{lc}
\hline \multicolumn{1}{c}{ Substrate } & \multicolumn{1}{c}{$K_{m}$} \\
& $(\mathrm{M})$ \\
\hline & \\
NAD & $0.0004 \pm 0.0001$ \\
Ethanol & $0.40 \pm 0.09$ \\
1-Propanol & $0 \cdot 12 \pm 0.03$ \\
1-Butanol & $0 \cdot 02 \pm 0.01$ \\
2-Fluoroethanol & Slightly reactive* \\
Acetaldehyde & Slightly reactive* \\
Methanol & No activity \\
Retinol & No activity \\
& \\
\hline
\end{tabular}

Activity of alcohol dehydrogenase was assayed as described in Methods. When the $K_{m}$ of NAD was determined, 1.0 M-ethanol was the co-substrate. When acetaldehyde was tested, $2 \mathrm{~mm}-\mathrm{NADH}$ was employed in reaction mixtures, and reactions were carried out from $\mathrm{pH}$ 6.5 to $\mathrm{pH} 9 \cdot 0$. Phosphate $(0.05 \mathrm{M}$-potassium phosphate) or sodium pyrophosphate $(0.05 \mathrm{M})$ buffers were used. Retinol was solubilized by the method used for studies with hepatic ADH (REYNIER, 1969). Concentrations up to $10 \mathrm{mM}$ retinol were employed.

Each value represents the mean \pm S.E.M. of at least three determinations.

* Concentrations of 2-fluoroethanol and acetaldehyde were $2.0 \mathrm{M}$ and $0.1 \mathrm{M}$, respectively.

Recently, REYNIER (1969) showed that hepatic ADH effectively catalysed oxidation of retinol to retinaldehyde, an observation confirmed in our laboratory. Methanol is a substrate for hepatic $\mathrm{ADH}$, although the value of its $K_{m}$ with the hepatic enzyme is about 20-fold that of ethanol (MAKar, TEPHLY and MANNERING, 1968). Ethanol, 1-propanol and 1-butanol also served as substrates for RADH, although their $K_{m}$ values were about 100 to 1000 -fold higher than those reported for hepatic ADH (THEORELL and BONNICHSEN, 1951). As observed characteristically with the hepatic enzyme, the value for the $K_{m}$ decreased with increasing length of the carbon chain. 2-Fluoroethanol has 
been employed as a substrate for hepatic $\mathrm{ADH}$ in order to distinguish several types of hepatic ADH (TREBLE, 1962). RADH was reactive with 2-fluoroethanol only at extremely high concentrations $(2.0 \mathrm{M})$. Another notable property of RADH was its relatively poor activity with acetaldehyde as substrate under conditions in which acetaldehyde functions effectively as a substrate with the hepatic enzyme. Further studies on this property of the enzyme are currently under way.

To establish further that RADH was unreactive with retinol, five additional assays were employed: (1) the direct spectrophotometric measurement of the formation of retinaldehyde (REYNIER, 1969); (2) a colorimetric assay of the retinaldehyde-paminobenzoic acid complex (MALLIA and CAMA, 1969); (3) the coupling of RADH to lactaldehyde whereby the formation of propanediol was linked to the oxidation of alcohol substrate (GUPTA and RoBINSON, 1966); (4) kinetic studies on the possible inhibition by retinol of ethanol oxidation; and (5) activity stains of RADH on polyacrylamide gels using retinol as substrate. In each case Tween-80 and acetone were employed in various concentrations in order to facilitate the solubilization of retinol. This technique has been employed by others (REAding and SorsBy, 1966; Koen and SHAw, 1966). Concentrations effective for solubilization displayed no substrate or inhibitory properties in these assays. In each of the five assays there was no suggestion of the interaction of retinol with $\mathrm{RADH}$, although ethanol did yield measurable activity when employed as a substrate. Also, activity was observed when hepatic cytosol was used with retinol. Therefore, we conciuded that retinol was not a substrate for RADH, although it did react with hepatic ADH.

Effect of inhibitors. Pyrazole and butyraldoxime are potent inhibitors of hepatic ADH (Lester et al., 1968; KoE and TENEN, 1969). The competitive inhibition of ethanol oxidation by pyrazole and butyraldoxime is illustrated in Fig. 2 . The $K_{i}$ observed for pyrazole was $5 \times 10^{-4} \mathrm{M}$ and the $K_{i}$ for butyraldoxime was $2 \times 10^{-6} \mathrm{M}$. For hepatic ADH, the $K_{l}$ of pyrazole is about $4 \mu \mathrm{M}$ (REYNIER, 1969). Recent studies in

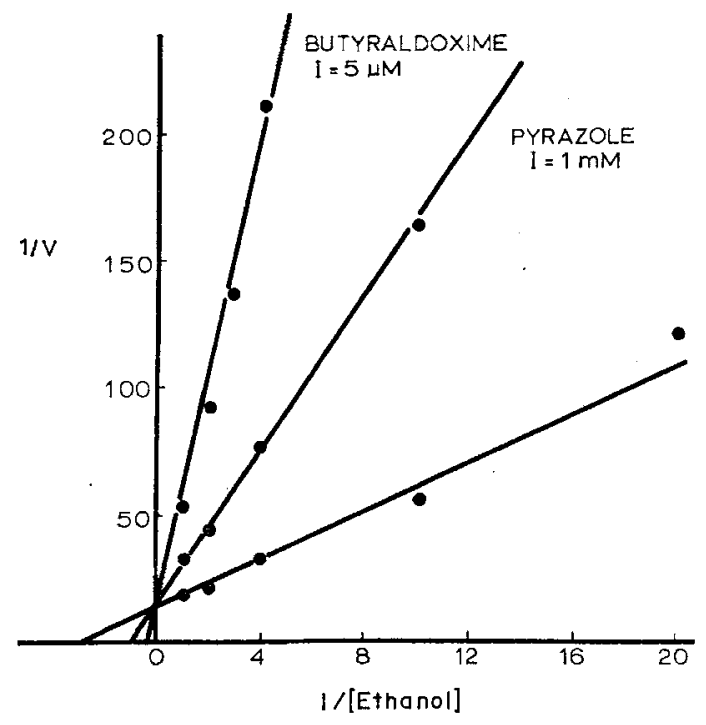

Fig. 2.-A LineweAver-BURK (1934) plot of the effects of pyrazole and $n$-butyraldoxime on the activity of retinal alcohol dehydrogenase. See text for discussion. 
this laboratory have shown that the $K_{t}$ for butyraldoxime with hepatic ADH is about $8 \mu \mathrm{M}, 1,10-$ Phenanthroline is a zinc chelating agent which is a potent inhibitor of hepatic ADH (SUND and THEORELL, 1963). Inhibition of RADH was observed only at relatively high concentrations of 1,10 -phenanthroline $(10 \mathrm{~mm})$, a finding that suggested that RADH is not a zinc-containing enzyme and that the retinal ADH is a different enzyme distinct from the hepatic ADH.

Oxidation of retinol in retinal homogenates. KOEN and SHAw (1966) have shown that certain retinal ADH isoenzymes exhibit activity on starch gel in the presence of retinol. Since their preparations could have included certain particulate fractions we decided to examine oxidation of retinol in homogenates of rat retina. Although no activity was observed in cytosol fractions of rat retina, homogenates were capable of supporting retinol oxidation (Table 4) when $\mathrm{NADP}^{+}$was added to the reaction

TABLE 4.-OXIDATION OF RETINOL IN HOMOGENATES OF RAT RETINAE

\begin{tabular}{lcc}
\hline & \multicolumn{2}{c}{$\begin{array}{c}\text { Retinol oxidation } \\
(\mu \mathrm{mol} \text { of retinaldehyde/g of retina/h }) \\
\text { I }\end{array}$} \\
\hline II
\end{tabular}

Retinal homogenates were incubated with $1 \cdot 1 \mathrm{~mm}$ retinol, 2 mM-NADP and, when used, 1 mu-pyrazole, 100 mis-ethanol or $100 \mathrm{~mm}$-methanol in a final volume of $1.5 \mathrm{ml}$ with $0.1 \mathrm{M}$-potassium phosphate buffer $(\mathrm{pH} 7 \cdot 6)$. Reactions were carried out in air at $37^{\circ} \mathrm{C}$ for $60 \mathrm{~min}$, during which time product formation was linear.

Each set of values represents an individual experiment.

mixture. Pyrazole (1 mM), ethanol (100 mM) and methanol (100 mM) were incapable of inhibiting oxidation of retinol in this preparation. These data agree with the observations of FUTTERMAN (1963) who has shown that NADP ${ }^{+}$is an active co-substrate in preparations of visual cell outer segments. We used NADP ${ }^{+}$in this study because it was about twice as active as $\mathrm{NAD}^{+}$in the rat retinal homogenate for support of the oxidation of retinol to retinaldehyde.

\section{Discussion}

We have isolated and partially purified an NAD-dependent alcohol dehydrogenase $(A D H)$ from rat retinal cytosol and have evaluated its possible role in regeneration of visual pigments. Previous studies of retinal ADH have involved relatively crude preparations (WALD and HubBard, 1949; 1963; MuIRHEAD, 1967; READING and SORSBY, 1966; KOEN and SHAw, 1966), a limitation that has hindered interpretations. Furthermore, even in relatively impure retinal preparations doubt has been cast on the participation of retinal ADH in oxidation of retinol (KOEN and SHAw, 1966). KOEN and SHAw (1966) used retinal and hepatic extracts and concluded on the basis of starch-gel 
electrophoresis, heat inactivation, inhibition studies and $\mathrm{pH}$ studies that retinol was oxidized in the retina and liver by specific and distinct enzymes. Our present investigation shows that NAD-dependent, retinal oxidation of ethanol is catalysed by an enzyme purified from the retinal cytosol fraction and that it has no catalytic activity with respect to oxidation of retinol. This enzyme exhibits relatively poor activity with ethanol as substrate and is unreactive with methanol. Although there is some similarity to hepatic ADH in the decreasing values for $K_{m}$ with increasing length of the substrate carbon chain, dissimilarities are outstanding. Retinal ADH is insensitive to 1,10phenanthroline and is a poor catalyst of acetaldehyde reduction. With hepatic ADH, acetaldehyde reduction is greatly favoured over alcohol oxidation (SUND and THEORELL, 1963).

Because retinol is relatively insoluble in aqueous solutions, solubilizing agents such as Tween-80 or acetone are usually employed. It is conceivable that the inclusion of such substances in reactions with retinal enzymes inhibits a retinol oxidizing enzyme. If so, it is unlikely that the enzyme is RADH because neither acetone nor Tween- 80 affected the activity of that enzyme toward ethanol. Similarly, these agents in the concentrations used in these studies have been reported to have no effect on hepatic ADH activity (REYNIER, 1969). In this, we concur. Despite the inhibition of retinal ADH by pyrazole and $n$-butyraldoxime, we think it unlikely that these substances could exert a retinotoxicity, on the basis of inhibition of oxidation of retinol. This view is substantiated by direct measurements of oxidation of retinol to retinaldehyde in homogenates of rat retina, where neither ethanol, methanol nor pyrazole inhibit retinol oxidation. Therefore, substances which may be retinotoxic and which might interfere with metabolism in the visual pigment cycle must be examined for their effects on oxidation of retinol and not for their effects on oxidation of ethanol.

The role of the hexose monophosphate shunt in generating NADPH which, in turn, can support reduction of retinaldehyde in retinal preparations has been explored by Futterman (1963) and FutTerman, Hendrickson, Bishop, Rollins and VACANo (1970). Recently, TABAKOFF and ERWIN (1970) have isolated an NADPHlinked aldehyde reductase (EC 1.1.1.2) from bovine brain which does not use ethanol as substrate and which is not sensitive to pyrazole. This enzyme catalyses the reduction of long chain aliphatic aldehydes and aromatic aldehydes such as benzaldehyde and substituted phenylacetaldehydes. It is possible that an enzyme with these characteristics is also involved in retinol-retinaldehyde interconversion.

Acknowledgements-The technical assistance of Mrs. FERNANDE TINELLI is gratefully acknowledged. The research was supported by USPHS grant GM-14209 and Training Grant TO1 ES00106 from the National Institute of Environmental Health Sciences.

\section{REFERENCES}

Buiss A. F. (1951) Archs Biochem. Biophys. 31, 197.

Blomstrand R. and Theorell H. (1970) Life Sci. 9, 631.

Cleland W. W. (1963) Nature, Lond. 198, 463.

Dietz A. A. and Lubrano T. (1967) Analyt. Biochem. 20, 246.

FutTerman S. (1963) J. biol. Chem. 238, 1145.

Futterman S., Hendrickson A., Bishop P. E., Rollins M. H. and Vacano E. (1970) J. Neurochem. $17,149$.

Gornall A. G., Bardwill C. S. and David M. M. (1949) J. biol. Chem. 177, 75.

Gupta N. K. and Robinson W. G. (1966) Biochim. biophys. Acta 118, 431.

Koe B. K. and TeneN S. S. (1969) Fedn Proc. Fedn Am. Socs exp. Biol. 28, 546. 
Koen A. L. and Shaw C. R. (1966) Biochim. biophys. Acta 128, 48.

Lester D., Keokosky W. Z. and Felzenberg F. (1968) Q. Jl Stud. Alcohol 29, 449.

LINEWEAVER H. and BURK D. (1934) J. Am. chem. Soc. 56, 568.

Lowry O. H., Rosebrough N. J., FARr A. L. and Randall R. J. (1951) J. biol. Chem. 193, 265.

Mallia A. K. and Cama H. R. (1969) Analyt. Biochem. 30, 86.

Makar A. B., Tephly T. R. and Mannerino G. J. (1968) Mol. Pharmac. 4, 471.

MuirHeAd J. F. (1967) Invest. Ophthal. 6, 635.

Raskin N. H. and Sokolofy L. (1968) Science, N.Y. 162, 131.

READING H. W. and SorsBy A. (1966) Biochem. J. 99, 3c.

REYNIER M. (1969) Acta chem. scand. 23, 3.

Sund H. and Theorell H. (1963) In The Enzymes (Edited by Boyer P. D., Lardy H. and Myrä̈ck K.) Vol. 7, p. 25. Academic Press, New York.

TABAKOFF B. and ERWIN V. G. (1970) J. biol. Chem. 245, 3263.

Theorell H. and BonNChSEN R. K. (1951) Acta chem. scand. 5, 1105.

Treble D. H. (1962) Biochem. J. 82, 129.

Wald G. and HubBard R. (1949) J. gen. Physiol. 32, 367.

Wald G. and HưbBard R. (1963) In The Enzymes (Edited by Boyer P. D., LARdy H. and Myrbäck

K.) Vol. 3, p. 369. Academic Press, New York.

WARBurg O. and Christian W. (1941) Biochem. Z. 310, 384.

WatKINS, W. D., GoOdMAN J. I. and TEPHLY T. R. (1970) Mol. Pharmac. 6, 567.

WiLkINSON G. N. (1961) Biochem. J. 80, 324.

Zachman R. D. and Olson J. A. (1961) J. biol. Chem. 236, 2309. 